\title{
Alexander Ivanovich Archakov
}

DOI: $10.1134 / \mathrm{S} 1990750810010014$

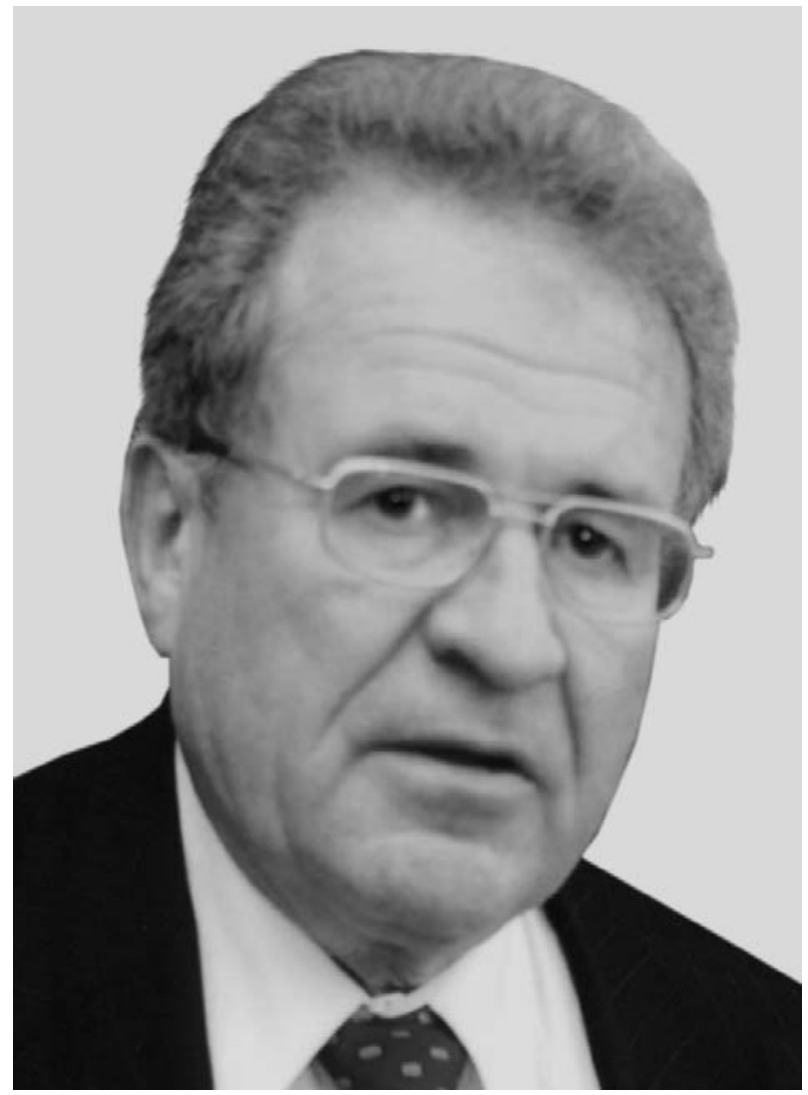

January 10, 2010 is the 70th birthday of the Series Editor of the Journal "Biochemistry (Moscow) Supplement Series B: Biomedical Chemistry", an outstanding scientist, Director of the Institute of Biomedical Chemistry, Russian Academy of Medical Sciences, academician of RAMS Alexander Ivanovich Archakov.

We cordially congratulate Alexander Ivanovich with his jubilee and wish very good health and a continuation of many prosperous years for his exceptionally fruitful work for Russian science and Public Health.

Usually people are judged by their actions and so this issue contains the Lecture by Alexander Ivanovich and papers prepared under his guidance. The publishing policy of the Series Editor A. I. Archakov limits publications of the author, A. I. Archakov, by 1-2 papers per issue. However, members of the Editorial Board and Deputy Editors of this Journal have decided to make an exception, which can demonstrate a spectrum of current research interests of Alexander Ivanovich and impressive results obtained by his colleagues!
January 10, 2010 is the 70th birthday of the Series Editor of the Journal "Biochemistry (Moscow) Supplement Series B: Biomedical Chemistry", an outstanding scientist, Director of the Institute of Biomedical Chemistry, Russian Academy of Medical Sciences, academician of RAMS Alexander Ivanovich Archakov.

We cordially congratulate Alexander Ivanovich with his jubilee and wish very good health and a continuation of many prosperous years for his exceptionally fruitful work for Russian science and Public Health.

Usually people are judged by their actions and so this issue contains the Lecture by Alexander Ivanovich and papers prepared under his guidance. The publishing policy of the Series Editor A. I. Archakov limits publications of the author, A. I. Archakov, by 1-2 papers per issue. However, members of the Editorial Board and Deputy Editors of this Journal have decided to make an exception, which can demonstrate a spectrum of current research interests of Alexander Ivanovich and impressive results obtained by his colleagues! 